\title{
IMPLEMENTASI PEMBELAJARAN KIMIA BERBASIS INKUIRI PADA MATERI TERMOKIMIA DI SMAN 1 SUNGAILIAT
}

\author{
Emiliya \\ SMAN 1 Sungailiat \\ e-mail: emiliya200312@gmail.com
}

\begin{abstract}
ABSTRAK
Penelitian ini bertujuan untuk melihat penerapan pembelajaran inkuiri terhadap penguasaan konsep dan partisipasi aktif peserta didik pada pokok bahasan termokimia di SMAN 1 Sungailiat. Tahapan pembelajaran berbasis inkuiri (learning sequence) meliputi discovery learning, interactive demontrations, inqury lesson, inqury laboratory, real word application dan hypothetical inquiry. Penelitian ini merupakan penelitian eksperimen. Dalam penelitian ini penulis mendeskripsikan gambaran proses yang terjadi pada saat dilaksanakannya pembelajaran di kelas dan intrumen data yang diambil adalah berupa hasil belajar dan partisipasi aktif peserta didik. Berdasarkan dari data penelitian diperoleh nilai rata-rata hasil belajar peserta didik nilai postes pada level discovery learning sebesar 86,06, interactive demontrations sebesar 90,92, inqury lesson sebesar 91,91, inqury laboratory sebesar 80,30, dan real word application 88,48 dengan persentase ketuntasan kelas tiap level berturut-turut 75\%, 72,72\%, 82\%, $81,81 \%$, dan $85 \%$. Sedangkan partisipasi aktif dalam bentuk diskusi kelompok, menyajikan pesentasi, melaksanakan praktikum dan mengerjakan lembar kerja peserta didik memperoleh kategori berturut turut cukup, cukup baik, dan baik. Dari data tersebut dapat disimpulkan bahwa pembelajaran kimia berbasis inkuiri dapat memperlihatkan hasil belajar yang baik hasil belajar dan partisipasi aktif dari peserta didik.
\end{abstract}

Kata Kunci: inkuiri, penguasaan konsep, partisipasi aktif

PENDAHULUAN 
Dewasa ini peserta didik dihadapkan pada tantangan abad 21. Sejalan dengan perubahan zaman, maka tuntutan karakteristik warga negara yang diperlukan pun berubah, pada abad 21 diperlukan warga negara yang mampu berpikir kritis, kreatif inovatif bekerja sama mampu berkomunikasi, kolaborasi dan memecahkan masalah untuk menopang produktivitas (Rotherham, dalam Poppy ; 2018)

SMAN 1 Sungailiat telah menerapkan Kurikulum 2013 mulai tahun pelajaran 2013/2014. Guru-guru di sekolah ini sudah mulai mencoba melaksanakan pembelajaran sesuai dengan yang sudah didapat melalui pelatihan kurikulum 2013. Sebanyak $95 \%$ dari guru yang bertugas di SMAN 1 Sungailiat sudah mengikuti diklat implementasi kurikulum 2013. Namun dalam praktik di lapangan hasilnya belum sesuai dengan yang diharapkan. Sebagian besar guru dalam pembelajaran di kelas masih kembali menggunakan metode lama seperti ceramah dan tanya jawab. Guru mata pelajaran Kimia jarang memanfaatkan laboratorium untuk melakukan praktikum sesuai dengan materi yang sedang diajarkan didalam kelas.

Berdasarkan pengamatan yang dilakukan penulis dalam semester yang lalu dari empat guru kimia yang ada hanya satu dua guru yang aktif dalam memanfaatkan laboratorium pada proses pembelajaran. Hal ini mengakibatkan hasil belajar peserta didik yang diharapkan kurang memuaskan seperti apa yang diharapkan. Berdasarkan dari hasil ulangan harian kimia yang selalu dilakukan oleh penulis ternyata cukup banyak peserta didik yang tidak tuntas sesuai dengan nilai KKM yang sudah ditetapkan sebelumnya. Untuk topik termokima pada tahun 2017 dari 36 peserta didik yg mengikuti ulangan harian hanya $21(61,11 \%)$ orang tuntas. Begitu juga terlihat dari hasil Ujian Nasional Berbasis Komputer pada tahun 2018, untuk sisiwa yang memilih kimia sebagai mata pelajaran pilihan sebanyak 24 (dua puluh empat) orang yang mengikuti mata pelajaran kimia maka diperoleh nilai tertinggi hanya 67,5 dan terendah 22,5 sedangkan rata rata nilai UNBK sebesar 45,83.

Penguasaan konsep dan soal soal IPA yang membutuhkan keterampilan berpikir tingkat tinggi masih rendah. Hal ini terlihat pada saat pembahasan soal soal 
latihan yang berupa jenis soal HOTS ternyata peserta didik sukar untuk menjawabnya dengan benar. Begitu juga pengalaman belajar dari peserta didik melalui pendekatan saintifik (mengamati, menanya, mengumpulkan informasi, mengasiosiasi dan mengkomunikasikan) yang harus dimiliki peserta didik dalam praktikum dilaboratorium, tidak terlihat. Berdasarkan uraian diatas maka penulis mencoba untuk mengatasi masalah tersebut dengan menerapkan pembelajaran IPA berbasis inkuiri.

Berdasarkan uraian yang telah dipapar pada latar belakang masalah maka rumusan masalah dalam penelitian ini adalah : Apakah melalui pembelajaran kimia berbasis inkuiri pada pokok bahasan termokimia, penguasaaan konsep peserta didik kelas XI MIPA 4 di SMAN 1 Sungailiat akan dikatogorikan baik dan apakah melalui pembelajaran Kimia berbasis inkuiri pada pokok bahasan termokimia, partisipasi aktif peserta didik kelas XI MIPA 4 di SMAN 1 Sungailiat akan baik.

Penelitian ini bertujuan untuk menerapkan pembelajaran inkuiri sebagai usaha penguasaan konsep dan partisipasi aktif peserta didik pada pokok bahasan termokimia pada peserta didik kelas XI MIPA 4 di SMAN 1 Sungailiat.

\section{METODE}

Penelitian ini menggunakan metode penelitian eksperimen, dimana dalam penelitian ini penulis mendeskripsikan gambaran proses yang terjadi pada saat dilaksanakannya pembelajaran di kelas dengan menggunakan pembelajaran kimia berbasis inkuiri.

Subjek dalam penelitian ini adalah peserta didik kelas XI MIPA 4 yang berjumlah 33 orang yang terdiri dari 11 laki laki dan 22 perempuan pada SMAN 1 Sungailiat Jl. Pemuda Sungailiat Bangka Provinsi Kepualaun Bangka Belitung.

Waktu yang digunakan untuk pembelajaran ini adalah 12 JP atau $6 \mathrm{x}$ pertemuan@2JP

Keterampilan praktik sains dan keterampilan intelektual pada pembelajaran topik termokimia meliputi : (a) Level discovery learning: membangun konsep, 
mengkontekstualkan, menyimpulkan dan menggeneralisasikan (b) Level interactive demonstration: menjelaskan dan memprediksi. (c) Level inquiry lesson: menerapkan informasi, menjelaskan, memaknai data kuantitatif untuk mencari hubungan matematis (d) Level inquiry laboratory: Merancang dan melakukan penyelidikan ilmiah yang terkontrol dan Menggunakan data, analisis grafis, dan matematika dalam pemecahan masalah ilmiah (e) Level real-world applications: menggunakan data dan matematik dalam pemecahan masalah dunia nyata, merangkum secara logis membenarkan sebuah kesimpulan berdasarkan bukti empiris, dan menggunakan penalaran yang tepat untuk membuat prediksi.

Media pembelajaran yang diperlukan dalam pembelajaran termokimia adalah : Bahan tayang Lembar kerja Multimedia : LCD, PC/Laptop, speaker. Alat praktik yang digunakan adalah kalorimeter sederhana, termometer, gelas kimia dan gelas ukur Bahan Kimia yang digunakan adalah aquades, $\mathrm{HCl}, \mathrm{NaOH}, \mathrm{CaO}$, $\mathrm{NH}_{4} \mathrm{Cl}, \mathrm{Ba}(\mathrm{OH})_{2} .5 \mathrm{H}_{2} \mathrm{O}$, Urea dan $\mathrm{NaCl}$, pita $\mathrm{Mg}$ Alur pembelajaran berbasis inkuiri pada topik konfigurasi elektron digambarkan sebagai berikut.
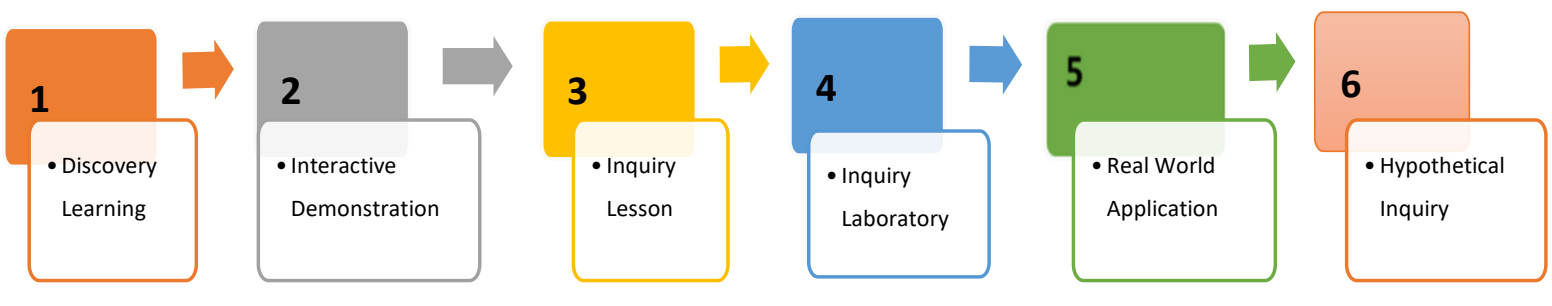

Teknik pengumpulan data dalam penelitian ini adalah berupa tes dan observasi. Instrumen yang digunakan untuk memperoleh data penguasaan konsep termokimia dilakukan dengan menggunakan tes per level inquiry, pretes dan pos tes. Sedangkan untuk motivasi belajar peserta didik berupa partisipasi aktif digunakan instumen observasi peserta dalam proses pembelajaran di kelas.

Sebagai observer dalam mengambilan data ini adalah penulis langsung melalui pengamatan saat pembelajaran berlangsung dan pengamatan melalui hasil rekaman video yang dilakukan saat proses pembelajaran dikelas. 


\section{HASIL DAN PEMBAHASAN}

Pada pembelajaran ipa berbasis inkuiri ini materi pokok yang disajikan penulis adalah termokimia. Hal ini sesuai dengan arahan yang diterima penulis dari widyaiswara PPPPTK IPA Bandung pada saat akan melaksanakan OJL di daerah tempat penulis bertugas. Pembelajaran melalui pertemuan tatap muka dilakukan selama 4 (hari) mulai dari tanggal 20 sampai dengan 23 Agustus 2018.

Tabel 1 Learning Sequence pembelajaran kimia topik Termokimia

\begin{tabular}{|c|c|}
\hline 1. Discovery Learning & 2. Interactive Demonstration \\
\hline $\begin{array}{l}\text { Peserta didik mempelajari gambar } \\
\text { fotosintesis dan mengamati reaksi } \\
\text { logam } \mathrm{Mg} \text { dan } \mathrm{HCl} \text { untuk memahami } \\
\text { konsep sistem dan lingkungan. } \\
\text { Peserta didik diminta mencari } \\
\text { informasi tentang entalpi reaksi, } \\
\text { perubahan entalpi, persamaan } \\
\text { termokimia, perubahan entalpi } \\
\text { standar menggunakan sumber } \\
\text { bacaan dan lembar kerja (LK) } \\
\text { Peserta didik melakukan percobaan untuk } \\
\text { menemukan pengertian reaksi eksoterm } \\
\text { dan endoterm. }\end{array}$ & $\begin{array}{l}\text { Peserta didik mengamati demonstrasi } \\
\text { percobaan reaksi penetralan antara larutan } \\
\mathrm{HCl} \text { dan } \mathrm{NaOH} \text {. Peserta didik diharapkan } \\
\text { mengajukan pertanyaan tentang jenis } \\
\text { reaksi dan perubahan entalpi reaksi pada } \\
\text { reaksi penetralan tersebut. Peserta didik } \\
\text { berdiskusi mengenai beberapa reaksi kimia } \\
\text { (Reaksi pembentukan dan reaksi } \\
\text { penguraian) } \\
\text { memprediksi nama perubahan entalpi reaksi } \\
\text { tersebut menggunakan lembar kerja yang } \\
\text { tersedia. }\end{array}$ \\
\hline
\end{tabular}




\begin{tabular}{|c|c|}
\hline 3. Inquiry Lesson & 4. Inquiry Laboratory \\
\hline $\begin{array}{l}\text { Peserta didik membedakan jenis-jenis } \\
\text { perubahan entalpi reaksi }\left(\Delta \mathrm{H}_{\mathrm{f}}{ }^{0}, \Delta \mathrm{H}_{\mathrm{d}}{ }^{0},\right. \\
\left.\Delta \mathrm{H}_{\mathrm{c}}{ }^{0} \text { dan } \Delta \mathrm{H}_{\mathrm{n}}{ }^{0}\right) \text { melalui tugas baca } \\
\text { menggunakan LK } \\
\text { Peserta didik mendiskusikan penentuan } \\
\text { perubahan entalpi secara eksperimen ( } \\
\text { cara kalorimeter atau Azas Black), } \\
\text { berdasarkan harga } \Delta \mathrm{H}_{\mathrm{f}}{ }^{0} \text {, hukum Hess } \\
\text { dan energi ikatan } \\
\text { Peserta didik latihan soal tentang } \\
\text { perubahan entalpi reaksi berdasarkan } \\
\text { entalpi pembentukan standar, hukum } \\
\text { Hess dan energi ikatan. }\end{array}$ & $\begin{array}{l}\text { Peserta didik merancang dan } \\
\text { melakukan percobaan penentuan } \\
\text { perubahan entalpi reaksi dalam } \\
\text { berbagai konsentrasi atau volume } \\
\text { larutan menggunakan kalorimeter } \\
\text { sederhana dan menghitungnya } \\
\text { menggunakan Azas Black } \\
\text { Peserta didik membuktikan berlakunya } \\
\text { hukum Hess melalui percobaan reaksi } \\
\text { antara } \mathrm{NaOH} \text { padat dengan larutan } \mathrm{HCl} \\
\text { dan larutan } \mathrm{NaOH} \text { dengan larutan } \mathrm{HCl}\end{array}$ \\
\hline $\begin{array}{l}\text { Peserta didik menggunakan } \\
\text { pengetahuannya untuk menghitung }\end{array}$ & 6. Hypothetical Inquiry \\
\hline
\end{tabular}




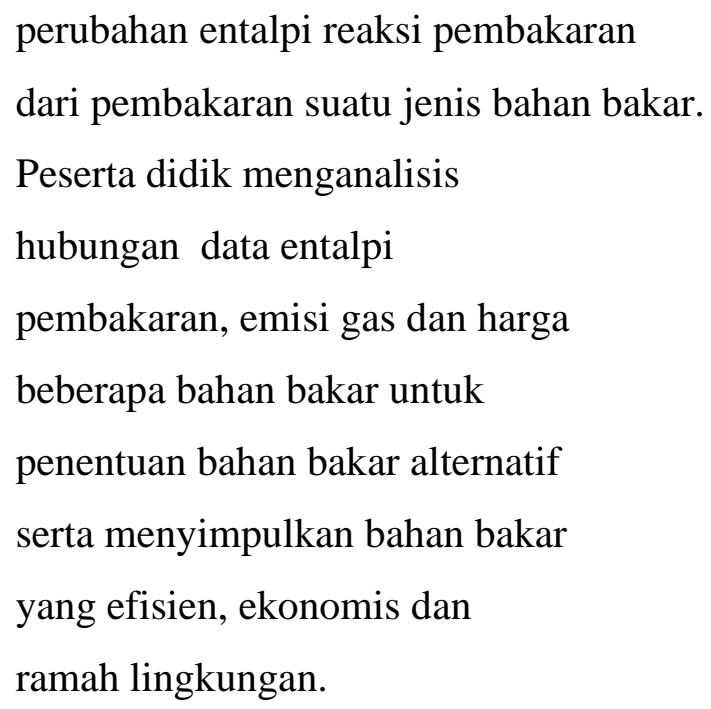

Pelaksanaan pembelajaran berbasis inkuiri

Langkah langkah pelaksanaan pembelajaran mulai dari level Discovery Learning sampai dengan Inquiry laboratory berpedoman pada RPP yang ada dan secara umum gambaran pelaksanaannya antara lain:

Kegiatan Pendahuluan dengan diawali guru memberikan salam pembuka, dan mengarahkan peserta didik untuk berdoa sebelum memulai pembelajaran. Selanjutnya guru menyampaikan materi pokok yang akan dipelajari, kompetensi dasar dan indikator pencapaian kompetensi yang harus dikuasai peserta didik. Kemuadian guru melaksanakan pretes kepada peserta didik sebelum pembelajaran dimulai. Guru membagi peserta didik dalam 6 kelompok yang heterogen baik dari jenis kelamin, kemampuan akademik, agama maupun etnis.

Kegiatan inti pembelajaran adalah kegiatan dimana guru dan peserta didik melakukan aktifitas pembelajaran dan mengerjakan LKPD sesuai dengan RPP/unit pembelajaran kimia berbasis inkuiri yang telah dipersiapkan.

Kegiatan Penutup pembelajaran adalah guru memberi penguatan terkait konsep termokimia. Guru juga melakukan penilaian dengan cara meminta peserta didik mengerjakan soal yang sudah tersedia. 
Partisipasi aktif yang dimaksud dalam dalam tulisan ini dilihat berdasarkan kriteria indikator yaitu aktif dalam diskusi selama pembelajaran berlangsung, aktif dalam menyajikan hasil kerja kelompok, aktif dalam melaksanakan praktikum, dan aktif dalam mengerjakan lembar kerja peserta didik.

Untuk mengetahui hasil belajar peserta didik selama mengikuti pembelajaran kimia berbasis inkuiri maka dilakukan penilaian diakhir pembelajaran setiap level/jenjang dan juga dilakukan penilaian pretes pada saat awal pertemuan pertama dan dan postes pada akhir pertemuan keempat. Hasil dari pada nilai peserta didik dapat terlihat dari gambar grafik 2 berikut ini :

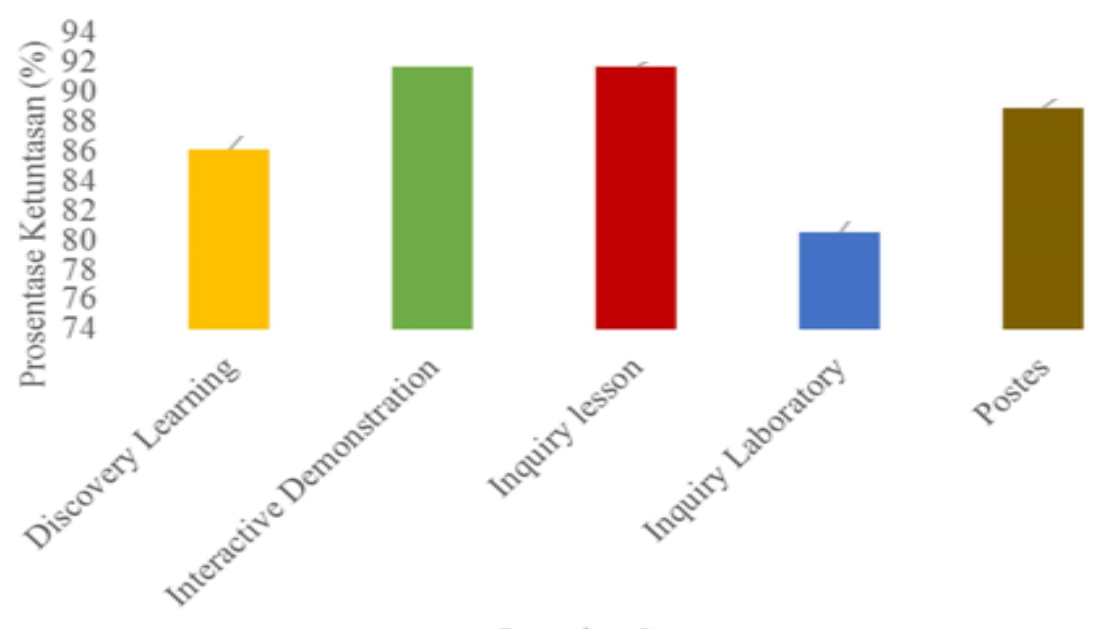

Learning Sequence

Gambar 1. Grafik Hasil Belajar Peserta Didik

Dari gambar 1 di atas, hasil belajar rata-rata siswa per level inquiry diperoleh nilai postest berturut turut sebesar 86,06 ; 90,92 : 91,91 : 80,30 dan 88,48. Dari data ini terlihat bahwa penguasaan konsep termokimia dari peserta didik telah mengalami peningkatan dibandingkan dengan pembelajaran dengan menggunakan metode ceramah dan tanya jawab. Untuk level inquiry laboratory terjadi penurunan sedikit nilai hasil belajar dibandingkan dengan level sebelumnya. Hai ini dapat dijelaskan pada level tersebut peserta didik dituntut lebih tinggi untuk mampu menguasai kompetensi 
sesuai dengan level tersebut terutama merancang percobaan berdasarkan pengetahuan yang sudah dimiliki pada level sebelumnya.

Untuk mengetahui sikap peserta didik selama proses pembelajaran berlangsung dimana yang diobservasi adalah partisipasi aktif, hasilnya dapat dilihat dari gambar 2 grafik partisipasi aktif peserta didik berikut ini:
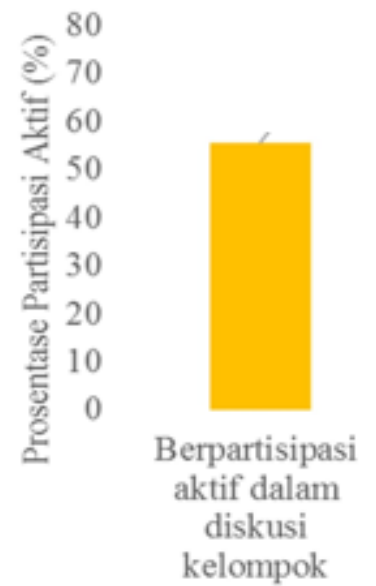

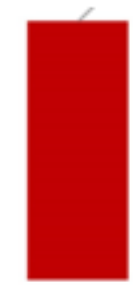

Berpartisipasi aktif dalam menyajikan hasil kerja kelompok

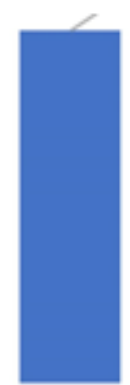

Berpartisipasi aktif dalam melaksanakan Praktikum

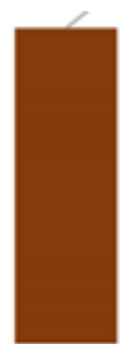

Berpasrtisipasi aktif dalam mengerjakan lembar kerja peserta didik

\section{Partisipasi Aktif Yang Dinilai}

\section{Gambar 2. Grafik Partisipasi Aktif Peserta Didik}

Untuk mengetahui keberhasilan proses pembelajaran dengan menggunakan model Pembelajaran Berbasis Inkuiri ini maka indikator yang digunakan adalah: perolehan nilai hasil belajar peserta didik secara klassikal dalam setiap level pembelajaran minimal adalah $80 \%$ sedangkan KKM per peserta didik sebesar 75 sesuai dengan yang ditetapkan untuk mata pelajaran kimia di kelas XI MIPA 4. Perolehan nilai rata rata sikap peserta didik berupa partisipasi aktif peserta didik dalam pembelajaran di kelas memenuhi kategori Baik (B).

Dikarenakan peserta didik belum pernah menerima pembelajaran dengan model pembelajaran kimia berbasis inkuiri ini maka pada saat pembelajaran berlangsung terutama di pertemuan pertama terlihat kondisi peserta didik masih banyak 
yang pasif dan monoton, tanya jawab tidak berlangsung secara produktif. Oleh karena itu guru memberi motivasi, stimulus dan pertanyaan yang lebih menarik dan menantang kepada peserta didik agar keterlibatan dan partisipasi aktif peserta didik dalam pembelajaran meningkat.

Guru kekurangan waktu dalam menyelesaikan tahapan tahapan pembelajaran sesuai dengan waktu yang sudah direncanakan sebelumnya. Untuk mengatasinya guru membuat time table yang lebih terinci sesuai dengan tahapan pembelajaran yang telah direncanakan. Peserta didik selalu diingatkan akan alokasi waktu yang tersedia terutama untuk diskusi kelompok/mengerjakan LKDP, presentasi kelompok dan praktikum.

Pelaksanaan diskusi kelompok dan presentasi yang dilaksanakan peserta didik kurang aktif dan hanya beberapa orang saja yang terlihat aktif bertanya atau menjawab pertanyaan. Diharapkan peranan ketua kelompok yang telah dihunjuk agar berperan aktif memotivasi dan mengarahkan teman teman untuk terlibat dalam diskusi/presentase. Ketua kelompok dipilih dari peserta didik yang memiliki nilai akademik relatif baik. Guru diharapkan memantau langsung ketempat masing-masing kelompok untuk mengawasi jalannya diskusi tersebut.

Saat praktikum berlangsung masih banyak peserta didik yang bekerja belum sesuai dengan lembar kerja yang ada. Penggunakan alat praktikum masih ada yang belum tepat sesuai dengan aturan. Pengambilan dan pengunaan zat kimia masih ada yang tidak sesuai dengan jumlah yang dibutuhkan. Sebelum praktikum berlangsung guru memberikan arahan yang jelas tentang pelaksanaan praktikum kepada peserta didik, bahan dan alat dipersiapkan dengan lengkap dan sudah tersedia di meja masing masing tiap kelompok.

\section{KESIMPULAN}

Kesimpulan dari Pembelajaran IPA berbasis inkuiri dapat meningkatan penguasahan konsep dan partisipasi aktif peserta didik pada materi termokimia kelas 
XI MIPA 4 di SMAN 1 Sungailiat. Pembelajaran IPA berbasis inkuiri ini hendaklah diterapkan oleh guru yang mengampu mata pelajaran fisika, kimia dan biologi di SMA sebagai salah satu model pembelajaran di sekolah.

\section{DAFTAR PUSTAKA}

Devi, Poppy, K Siti Kalsum, dkk. 2009. Kimia 2, Kelas XI SMA dan MA. Edisi BSE. Jakarta. Pusat Perbukuan Departemen Pendidikan Nasional

Kemdikbud. 2016. Permendikbud No.22 Tahun 2016 Tentang Peraturan Menteri Tentang Standart Proses Pendidikan Dasar Menengah. Jakarta.

Poppy K, Yayu dkk. 2018, Termokima, Unit Pembelajaran Kimia Berbasis Inkuiri PPPPTK IPA , Direktorat Jenderal Guru dan Tenaga Kependidikan Kementerian Pendidikan dan Kebudayaan.

Wenning, C.J. 2017. Scientific Practices and Intelectual Skills. Framework for Science Reasoning Literacy Test (SciReLit) by Hanson and Wenning based on Level of Inquiry Model of Science Teaching by Carl J.Wenning. Edisi 8 